\title{
Buckwheat Transformed with cDNA of a Rice MADS Box Gene Is Stimulated in Branching
}

\author{
Mineo KOJIMA*1), Mio HIHARA*, Shun-ichi KOYAMA*, Hidenari SHIOIRI*, Masayuki NOZUE*, \\ Kimiko YAMAMOTO** and Takuji SASAKI*** \\ *Department of Applied Biology, Faculty of Textile Science and Technology, Shinshu University, \\ 3-15-1 Tokida, Ueda, Nagano 386-8567, Japan \\ **Rice Genome Program (RGP), Society for Techno-innovation of Agriculture, Forestry and Fisheries \\ (STAFF), 446-1 Ippaizuka, Kamiyokoba, Tsukuba, Ibaraki 305-0854, Japan \\ ***Rice Genome Program (RGP), National Institute of Agrobiological Resources (NLAR), 2-1-1 \\ Kannondai, Tsukuba, Ibaraki 305-8602, Japan \\ ${ }^{1)}$ Corresponding author E-mail address :
}

Received 9 August 1999; accepted 2 November 1999

\begin{abstract}
Apical meristems of buckwheat (Fagopyrum esculentum var. Shinano No. 1) seedlings were transformed by inoculation with Agrobacterium tumefaciens harboring a binary vector containing cDNA of a rice MADS box gene (accession No. (DDBJ) AB003325) in either a sense or an antisense orientation downstream of CaMV35S promoter. The plants transformed (T0) with the cDNA in both orientations showed unique features; the plants transformed with the cDNA in a sense orientation were stimulated in branching, producing many branches, while the plants transformed with the cDNA in antisense orientation were inhibited in both branching and growth. The progenies (T1 plants) of both transformed plants inherited the nature of the respective T0 plant. The analyses using the Southern blot hybridization and PCR revealed that a single copy of the cDNA was integrated in the genomes of T1 plants in sense and antisense orientations, respectively.
\end{abstract}

\section{Introduction}

The biochemical functions and phenotypes of plants and other organisms are determined by the information encoded within the DNA sequences of their genomes and by the interaction of that information with the environment. Therefore, an important way to elucidate complex biological phenomena is to determine the DNA sequence of all genes in the genome and define their functions. Thus genome projects are in progress with plants such as Arabidopsis and rice, and a large number of genes or open reading frames have already been identified. However, the functions of only a limited number of genes among the genes identified have been defined, although sequence homologies and consensus sequence or motifs suggest possible functions for some of the identified genes.

In order to define the functions of the identified genes, it is prerequisite that the genes can be easily introduced into plants, producing the transgenic plants and that their progeny can be easily obtained in short period. We have recently developed such a simple and efficient transformation method using $A$. tumefaciens and buckwheat (accepted for publication in Biosci. Biotechnol. Biochem.). We wanted to test this transformation method using the defined genes of buckwheat. Unfortunately, however, no defined genes of buckwheat were available. Therefore, we tested this method using a rice cDNA (accession No. (DDBJ), AB003325) which had recently been cloned and defined (Shinozuka et al., 1999). The cDNA was expressed at a low level in panicles of rice. The complete nucleotide sequence of the cDNA were determined (Fig. 1). Its sequence was highly homologous to those of MADS box genes. MADS box genes represent a large multigene family in vascular plants (Riechmann and Meyerowitz, 1997). In angiosperms, many of the genes of MADS family are involved in the various steps of flower development. MADS box proteins are classified into 4 main groups, AP3, PI, AG and AP1, based on characteristics of their amino acid sequence. Dendrogram analysis suggested that the rice cDNA used in this study belonged to AP1 group. The AP1 MADS box genes have been reported to be involved in the specification of sepal and petal 


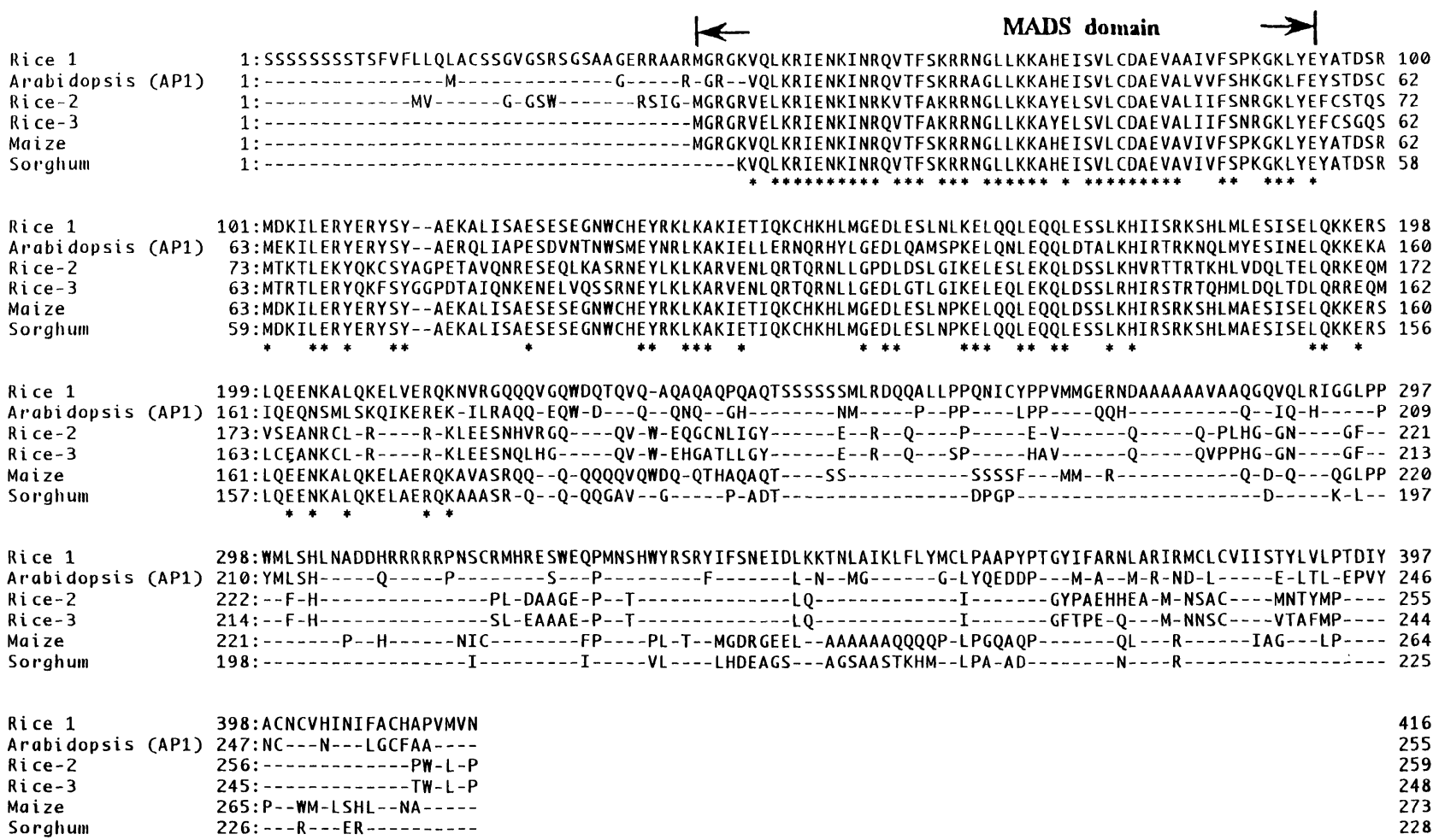

Fig. 1 Multiple alignment of deduced amino acid sequences of the cDNA of a rice MADS box gene used in this paper and some other MADS box genes. The alignment was obtained by the program Malign in GENETYX (Software Development Co., Ltd.) Gaps $(\cdots .$.$) ) were introduced for optimal alignment. The asterisks at the bottom show the$ amino acid residues that are invariantly conserved among them. The MADS domain are indicated on the top. Rice-1, Oryza sativa, (used in this paper, E31864, Shinozuka et al., 1999, accession No. AB003325); Arabidopsis (AP1), Arabidopsis thaliana (APETALA1, Mandel et al. 1992, accession No. Z1642); Rice-2, O. sativa, (Os MADS 7, Kang et al. 1997, accession No. XU073-0018); Rice-3, O. sativa, (Os MADS 8, Kang et al. 1997, accession No. U78892); Maize, Zea mays (ZAP1, Mena et al. 1995, accession No. L46400); Sorghum, Sorghum bicolor (Sb MADS 2, Greco et al. 1997, accession No. U32110).

identity (Mandel et al., 1992; Gustafson-Brown et al., 1994).

Previously, Kang et al. (1997) characterized the two rice MADS box genes, Os MADS 7 and Os MADS 8, of which nucleotide sequences were different from that of the cDNA used in this paper (Fig. 1). When cDNAs of the MADS box genes were expressed ectopically using the CaMV 35S promoter in a heterologous tabacco plant system, the transgenic plants exhibited the phenotype of early flowering and dwarfism. Thus, they concluded that these two rice MADS box genes are involved in controlling flowering time.

As mentioned above, most of the MADS box genes play a role in flower development and are expressed specifically in floral organs. However, some MADS box genes have been reported to be expressed in non-floral organs; AGL11 and AGL13 MADS box genes of Arabidopsis are preferentially expressed in ovules (Rounsley et al., 1995). AGL15 is expressed in embryos, whereas AGL12, AGL14 and AGL17 are all preferentially expressed in roots. The MADS box gene (GAG2) of ginseng is expressed in seedlings. As the ginseng plant grows, however, the expression of GAG2 is confined to flowers (Kim et al., 1998). Based on these RNA expression analyses, it has been proposed that in addition to their proven role in flower development, MADS box genes are likely to play a role in many other aspects of plant development (Rounsley et al., 1995).

The buckwheat transformed with the cDNA of a rice MADS box gene (AB003325) did not show any alterations in development and structure of flower. Instead, they showed a clear alteration in branching.

\section{Materials and Methods}

\subsection{Plant material, transformation and pollination}

The seeds of buckwheat (Fagopyrum esculentum 
var. Shinano No. 1) were sterilized with sodium hypochlorite and then sown on soil in pots and grown at $25{ }^{\circ} \mathrm{C}$ under $8 \mathrm{~h}$ light and $16 \mathrm{~h}$ dark. When the plants grew to the seedlings of 7-8 $\mathrm{cm}$ height with two expanded cotyledons 4 to 5 days later, apical meristems were pricked with a needle and inoculated with water suspension (ca. $1.0 \times 10^{8}$ cells $/ \mathrm{ml}$ ) of Agrobacterium tumefaciens harboring a binary vector. The inoculated seedlings were kept at $22{ }^{\circ} \mathrm{C}$ in the dark for 3 days and were subsequently grown at $30^{\circ} \mathrm{C}$ with $8 \mathrm{~h}$ illumination at about 4,000 Lux in a growth chamber.

Buckwheat plants develop two types of flowers with different lengths of pistil, about 1.8 and 0.6 $\mathrm{mm}$ (heterostylism). Only pollination between different types of flowers results in fertilization.

\subsection{A. tumefaciens and binary vectors}

A. tumefaciens (LBA4404) and a binary vector (pBI121) were obtained from Toyobo Co. Ltd. The binary vectors were introduced into $A$. tumefaciens (LBA4404) by transformation according to the reported methods (Holsters et al., 1978). A. tumefaciens was cultured in LB medium containing kanamycin $(50 \mu \mathrm{g} / \mathrm{m} l)$, rifampicin $(10 \mu \mathrm{g} / \mathrm{ml})$ and streptomycin $(50 \mu \mathrm{g} / \mathrm{ml})$ at $28{ }^{\circ} \mathrm{C}$ for $18 \mathrm{~h}$. The cells were harvested by centrifugation, washed with water, suspended in water $\left(1.0 \times 10^{8}\right.$ cells $\left./ \mathrm{ml}\right)$ and used as an inoculum.

$\beta$ - Glucuronidase (GUS) gene in a pBI121 vector was replaced with cDNA $(1.3 \mathrm{~kb})$ of a rice MADS box gene (accession No. (DDBJ) AB003325) in a sense orientation as follows.

A pBluescript (Stratagene) plasmid containing the cDNA in a SalI (5')/Not I (3') site was digested with SalI, then blunt-ended and finally digested with Sac I. The digested sample was applied to electrophoresis to recover a $1.3 \mathrm{~kb}$ fragment. A pUC18 (Nippon Gene) plasmid containing the segment $(3.1 \mathrm{~kb})$ from pBI121 that included the CaMV 35S promoter, a GUS gene and a Nos terminator, in its Hind III / Eco RI site was digested with Sma I and SacI. The digested sample was subjected to agarose gel electrophoresis to recover a $4.0 \mathrm{~kb}$ fragment. The $1.3 \mathrm{~kb}$ fragment and the $4.0 \mathrm{~kb}$ fragment were ligated and transformed to $E$. coli (JM109). A plasmid was isolated from a positive colony and digested with Bam $\mathrm{HI}$ and Sac I to obtain the cDNA $(1.3 \mathrm{~kb})$. The cDNA with a Bam HI and $S a c$ I ends thus obtained was ligated to a pBI121 vector from which the GUS gene had been removed by digestion with Bam HI and SacI. The ligated DNA was first transformed to E. coli (HB101) and then $A$. tumefaciens (LBA4404).

A pBI121 vector of which GUS gene was replaced with the cDNA in antisense orientation was prepared as follows. A plasmid (pBluescript) containing the cDNA $(1.3 \mathrm{~kb})$ in a Sal I $\left(5^{\prime}\right) / N o t \mathrm{I}$ (3') site was digested with Not I, then blunt-ended and finally digested with KpnI. The digested sample was applied to agarose gel electrophoresis to recover a $1.3 \mathrm{~kb}$ fragment. A pUC18 plasmid was digested with Bam HI, then blunt-ended and subsequently digested with KpnI. The digested sample was electrophoressed to recover a $2.6 \mathrm{~kb}$ fragment. The $2.6 \mathrm{~kb}$ fragment from pUC18 plasmid was ligated with the $1.3 \mathrm{~kb}$ fragment, and then transformed to $E$. coli (HB101). A plasmid was isolated from a positive colony and digested with $S a c$ I and $X b a \mathrm{I}$ to release the cDNA $(1.3 \mathrm{~kb})$ with $S a c \mathrm{I}$ and $X b a \mathrm{I}$ ends. Finally the cDNA was ligated with pBI121 vector which had been digested with $S a c$ I and $\mathrm{Xba}$ I.

\subsection{Isolation of genomic DNA from buckwheat}

Genomic DNA was extracted from either seedlings or mature plants using a Nuclear Phytopure DNA extraction kit (Amersham Pharmacia Biotech) following the instructions of supplier. The extracted DNA was further purified by the following procedures; the DNA was dissolved in $500 \mu \mathrm{l}$ of $10 \mathrm{mM}$ Tris- $\mathrm{HCl}$ (pH 8.0) buffer containing 1 mM EDTA and incubated with $2 \mu l$ of RNase (Nippon Gene, 10 $\mathrm{mg} / \mathrm{ml})$ at $37{ }^{\circ} \mathrm{C}$ for $45 \mathrm{~min}$. Subsequently, $100 \mu l$ of the solution including $60 \mathrm{mM}$ Tris- $\mathrm{HCl}(\mathrm{pH} 7.8)$, $60 \mathrm{mM}$ EDTA and $3 \%$ SDS and $5 \mu l$ of proteinase $\mathrm{K}(10 \mathrm{mg} / \mathrm{ml})$ were added to the solution and incubated at $50{ }^{\circ} \mathrm{C}$ for $3 \mathrm{~h}$. The incubated solution was then sequentially extracted with phenol, a mixture of phenol and chloroform $(1: 1, \mathrm{v} / \mathrm{v})$, and chloroform. The DNA in solution was then ethanolprecipitated and washed with $70 \%$ ethanol.

\subsection{Genomic Southern hybridization}

The genomic DNA $(15 \mu \mathrm{g})$ from buckwheat was digested with restriction endonuclease, subjected to electrophoresis in agarose gel (1.0\%) and then transferred to a Hybond $\mathrm{N}^{+}$nylon membrane (Amersham Pharmacia Biotech). A ${ }^{32} \mathrm{P}$-labeled probe was synthesized by using the cDNA $(1.3 \mathrm{~kb})$ of a rice MADS box gene and a random primer DNA labeling kit (Takara), and then purified with a column of Sephadex G-50. The nylon membrane with the transferred DNA was first pre-hybridized in 5 times concentration of SSPE solution $(0.18 \mathrm{M}$ $\mathrm{NaCl}, 10 \mathrm{mM}$ sodium phosphate, $1 \mathrm{mM}$ EDTA at $\mathrm{pH}$ 7.7) containing 5 times concentration of Denhardt's solution, $0.5 \%$ SDS and $20 \mu \mathrm{g} / \mathrm{ml}$ of salmon sperm DNA at $65{ }^{\circ} \mathrm{C}$ for $1 \mathrm{~h}$. Thereafter ${ }^{32} \mathrm{P}$ labeled probe was added to the pre-hybridization 
solution and hybridization was continued at $65{ }^{\circ} \mathrm{C}$ for $18 \mathrm{~h}$. The membrane was washed in 2 times concentration of SSPE solution containing 0.1\% SDS at $20{ }^{\circ} \mathrm{C}$ for $10 \mathrm{~min}$ two times, then in SSPE solution containing $0.1 \%$ SDS at $65{ }^{\circ} \mathrm{C}$ for $15 \mathrm{~min}$ once, and finally in 0.1 times concentration of SSPE solution containing $0.1 \%$ SDS at $65{ }^{\circ} \mathrm{C}$ for $10 \mathrm{~min}$, two times. The hybridizing DNA bands were visualized with an image analyzer (Molecular Dynamics).

\subsection{PCR}

An aliquot (1-2 $\mu l, 500 \mathrm{ng})$ of genomic DNA from the transformed (T1) plants was added to a reaction mixture of $50 \mu l$ of final volume $(50 \mathrm{mM}$ $\mathrm{KCl}, 10 \mathrm{mM}$ Tris- $\mathrm{HCl}, \mathrm{pH} 8.3,1.5 \mathrm{mM} \mathrm{MgCl}_{2}, 200$ $\mu \mathrm{M}$ each nucleotide, $0.2 \mu \mathrm{M}$ each primer, 1.25 units Taq polymerase (Takara)). The PCR reaction was conducted at $94{ }^{\circ} \mathrm{C}$ for $30 \mathrm{~s}$, at $58{ }^{\circ} \mathrm{C}$ for $45 \mathrm{~s}$, at $72{ }^{\circ} \mathrm{C}$ for $90 \mathrm{~s}$ for the first 30 cycles and then at $72{ }^{\circ} \mathrm{C}$ for $10 \mathrm{~min}$. The primers used in the PCR reaction were: P1，5'-ACAATCCCACTATCCTTCGC-3' which corresponded to the sequence of 3'-terminal of CaMV 35S promoter upstream of the original GUS gene in a pBI121 binary vector; P2, 5'GTCACGACGTTGTAAAACGA-3' which corresponded to the sequences near the right border of T-DNA downstream of the original GUS gene in the binary vector (Fig. 5, panel A). By the PCR reaction described above, the $1.7 \mathrm{~kb}$ DNA fragment was expected to be amplified.

\section{Results and Discussion}

\subsection{Transformation of buckwheat seedlings with A. tumefaciens}

As described in Materials and Methods, apical meristems of seedlings were inoculated with $A$. tumefaciens for transformation and thereafter the seedlings were not treated to eliminate the Agrobacteria. Therefore, we examined the presence of the remaining Agrobacteria in T0 and T1 plants as follows; the whole seedlings (T0 plants) after inoculation were homogenized with the sterilized water in a mortar. The homogenates were spread out on LB medium plates containing kanamycin (50 $\mu$ $\mathrm{g} / \mathrm{m} l)$, rifampicin $(10 \mu \mathrm{g} / \mathrm{m} l)$ and streptomycin (50 $\mu \mathrm{g} / \mathrm{m} l)$ on which $A$. tumefaciens used for transformation could grow, and the plates were incubated at $28{ }^{\circ} \mathrm{C}$. The number of colony appeared on the plate decreased with the time after inoculation and only a few colonies appeared with the homogenate of seedlings 14 days after inoculation. Most of Agrobacteria were eliminated possibly by the defense action of the buckwheat plant. As for T1 plants, the seeds were sterilized in sodium hypochlorite solution and then germinated aseptically. The resultant seedlings were homogenized with the sterilized water and the homogenate was incubated on the LB medium plates containing the antibiotics mentioned above. No colonies appeared, confirming that $\mathrm{T} 1$ plants were free of Agrobacteria used for transformation.

\subsection{Transformation with cDNA of a rice MADS box gene}

The cDNA was inserted in the site of the removed GUS gene in a pBI121 binary vector in either a sense or an antisense orientation. These two modified and a non-modified pBI121 vector were introduced into $A$. tumefaciens (LBA4404), which were inoculated on each of 50 seedlings. Thirtythree plants of 50 plants inoculated with $A$. tumefaciens containing the cDNA in a sense orientation were stimulated in branching and formed many branches (Fig. 2, panel A-3), although there was a diversity among plants in the degree of branching. Any alterations in flower development and structure were not observed with these plants. The remaining 17 plants looked normal. After maturing, these plants showed a similar extent of branching to that in Fig. 6, in which the plant shapes of T1 plants are presented in a reduced scale. On the other hand, 30 of the 50 plants inoculated with $A$. tumefaciens containing the cDNA in an antisense orientation were inhibited in both branching and growth (Fig. 2, panel A-4). The degree of inhibition in branching and growth was also variable among these plants as with the above mentioned plants. Similarly, no changes in floral development and structure were visible with these plants. The remaining 20 plants were similar to the non-transformed plants. The panel B in Fig. 2 shows the most highly expressed phenotype that a plant transformed with the cDNA in a sense orientation exhibited. The plants transformed with a GUS gene showed a similar appearance to that of the non-transformed plants (Fig. 2, panel A-1 and 2).

Each flower of T0 plants that exhibited the highest degree of the transformed phenotype was pollinated with a different type of flower of the non - transformed plants. The resultant seeds were sown and grown to examine the phenotype of $\mathrm{T} 1$ plants (Fig. 3). About half of progeny (10 plants) of the plants transformed with the cDNA in both a sense and an antisense orientations inherited the nature of the respective T0 plant. The progeny of the plants transformed with the cDNA in a sense orientation were stimulated in branching (Fig. 3, panel A). In contrast, the progeny of the plant transformed with 


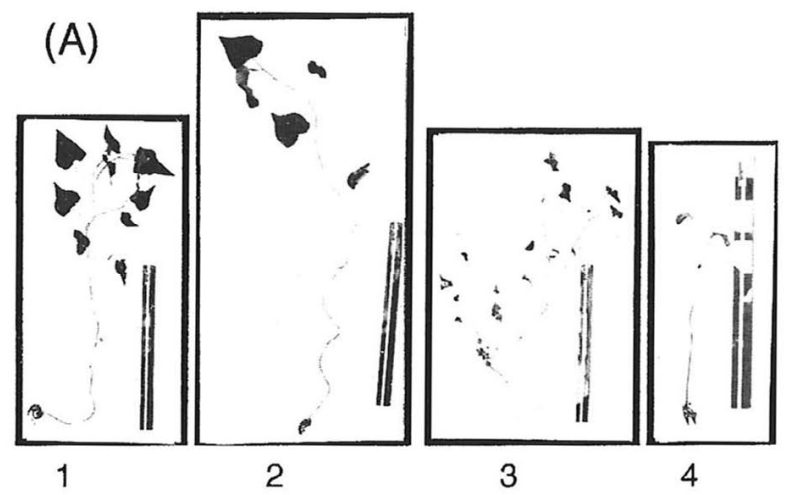

(B)

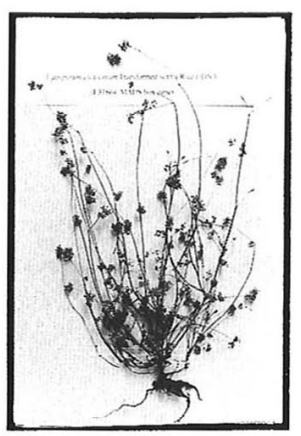

Fig. 2 Phenotypes of buckwheat plants transformed (T0) with the CDNA of rice MADS box gene. Panel A-1, non-transformed plant; panel A-2, A-3 and A-4 are the plants transformed with A. tumefaciens harboring a non-modified pBI121 vector, a pBI121 vector containing the cDNA in a sense and an antisense orientations, respectively. The photographs were taken one month after inoculation with $A$. tumefaciens. The bar in each photograph is a $36 \mathrm{~cm}$ rule. Note that the plant in panel $\mathrm{A}-3$ are stimulated in branching, while the plant in panel $\mathrm{A}-4$ is inhibited in branching. The panel $\mathrm{B}$ is the plant transformed with cDNA in a sense orientation that expressed most highly the transformed phenotype. The photograph was taken after the plant matured and died, 6 months later.

the cDNA in an antisense orientation were inhibited in both branching and growth (Fig. 3, panel B). Thus, the phenotype of the plants transformed with the cDNA in the opposite orientation was just of opposite to each other.

\subsection{Genomic Southern hybridization analysis of transformed (T1) plants}

The genomic DNAs from the non-transformed plants and the transgenic plants ( $\mathrm{T} 1$ plants) exhibiting the transformed phenotype were subjected to the Southern hybridization analysis using a ${ }^{32} \mathrm{P}$-labeled probe of the cDNA to demonstrate the integration of the cDNA in their genomes and to determine the number of integration of the cDNA (Fig. 4). The genomic DNAs were digested with
(A)

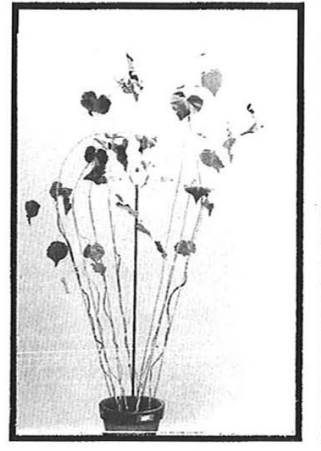

1

(B)

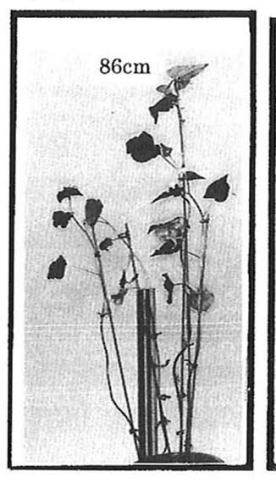

1
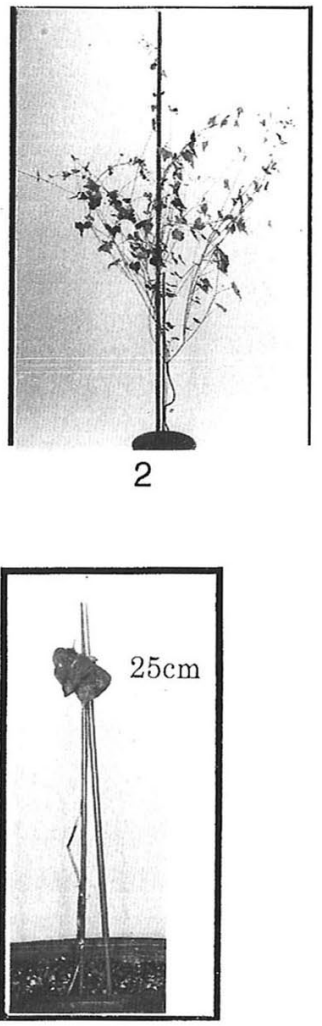

2
Fig. 3 Phenotypes of buckwheat plants transformed (T1) with the cDNA of a rice MADS box gene in a sense (panel A) and an antisense (panel B) orientation. Panel A; the 5 plants in the left (1) pot are the non-transformed plants and in the right (2) are the transformed plants. The photograph was taken 4 months after germination. Panel B; the 4 plants in the left (1) pot are the non-transformed plants and in the right plant (2) is the transformed plant. The photograph was taken 45 days after germination.

EcoRI, Sac I, Xho I and SalI, all of which have no restriction sites in the cDNA and subsequently applied to hybridization analysis. Only one hybridizing band was detected in every lane with both genomic DNAs (Fig. 4, panel A and B), indicating that a single copy of cDNA was integrated in genomes of both T1 plants analyzed.

No hybridizing band was detected with the genomic DNA from the non-transformed plant (Fig. 4, panel A and B). In this experiment, hybridization was done under the conditions of high stringency (see Materials and Methods). This might be the reason why an endogenous MADS box gene(s) of buckwheat was not detected. Alternatively, a MADS box gene(s) of buckwheat might not be homologous enough to the rice MADS box gene used in the present study in the region outside MADS domain. 


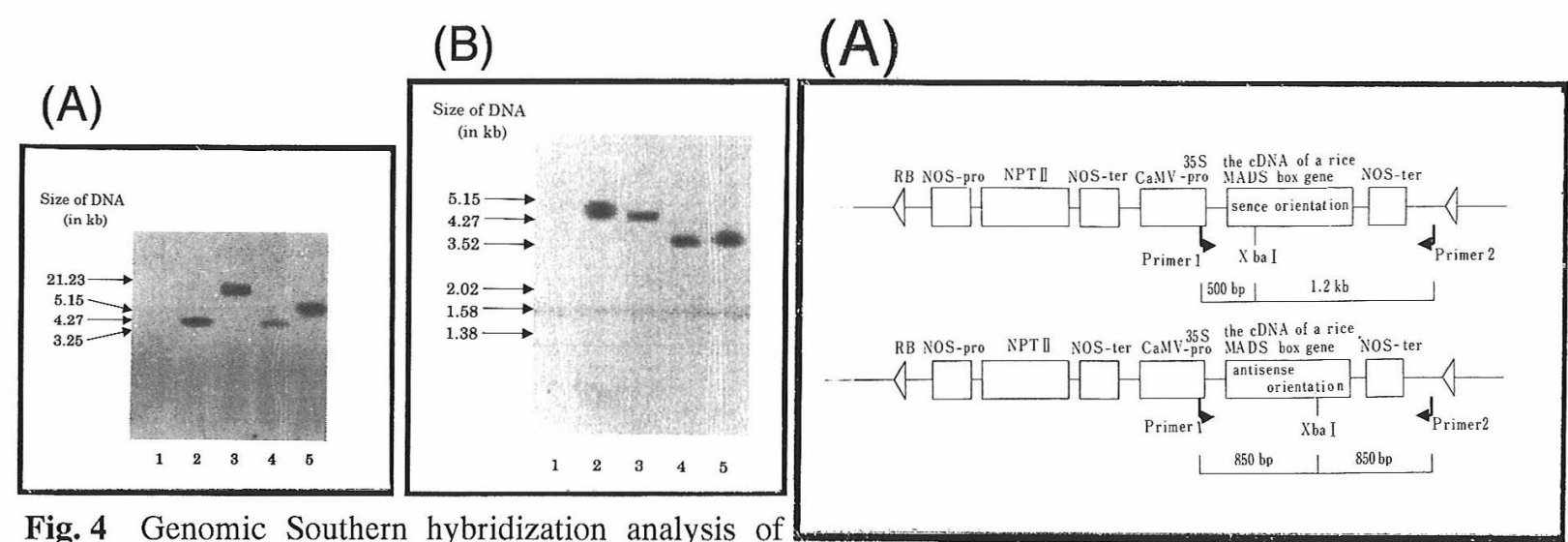

Fig. 4 Genomic Southern hybridization analysis of plant transformed (T1) with the cDNA of a rice MADS box gene in a sense (panel A) and an antisense (panel B) orientations. Genomic DNAs from the non-transformed and the transformed plants were digested with the enzymes which have no restriction site within the cDNA and analyzed using a ${ }^{32} \mathrm{P}$-probe of the cDNA. Lane 1; non-transformed, EcoRI digested; lane 2, transformed, EcoRI digested; lane 3, transformed, Sac I digested; lane 4, transformed, Xho I digested; lane 5, transformed, Sal I digested.

\subsection{Orientation of the cDNA integrated in the genome}

The two PCR primers were designed to amplify the cDNA integrated in the genome; one corresponded to the sequence of 3'-terminal of CaMV $35 \mathrm{~S}$ promoter which was located upstream of an original GUS gene in a pBI121 binary vector and another corresponded to the sequence near the right border downstream of an original GUS gene in the binary vector (Fig. 5, panel A). Using the primers, PCR was carried out with genomic DNAs from plants transformed (T1) with the cDNA in both a sense and an antisense orientations, which had been used in the genomic Southern hybridization analysis

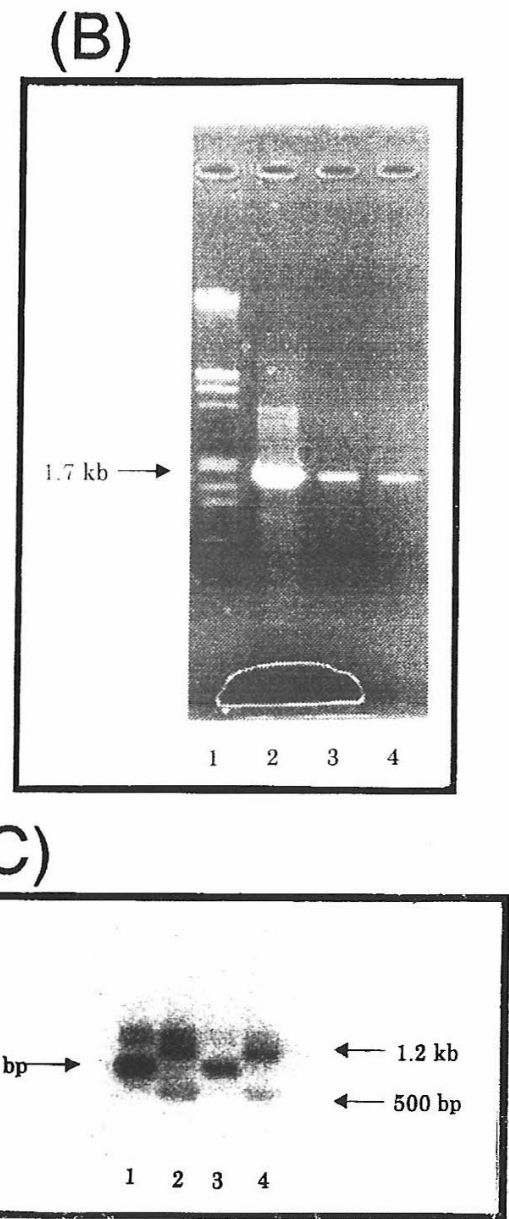

Fig. 5 Determination of orientation of the CDNA of a rice MADS box gene integrated in the genome. Panel A; the annealing sites of PCR primers used for amplification of the cDNA are indicated by the vertical lines and the directions of the polymerization reaction are shown with the arrows. The figures in base pair under the maps indicate the expected sizes of DNA fragments that are produced upon the digestion of the PCR products with $X b a$ I. Panel B; agarose gel (1\%) electrophoresis of the PCR products. After the reaction, the reaction mixtures were directly applied to electrophoresis and the gel was stained with ethidium bromide. Lane 1, DNA size marker; lane 2, PCR product of a binary vector with the cDNA in a sense orientation; lane 3, PCR product of genomic DNA from plants transformed (T1) with the cDNA in a sense orientation; lane 4, PCR product of genomic DNA from plants transformed (T1) with the cDNA in an antisense orientations. Panel C; Southern blot hybridization analysis. The PCR products were digested with $X b a \mathrm{I}$ and then subjected to the Southern blot hybridization using ${ }^{32} \mathrm{P}$-labeled probe of the cDNA. Lane 1, PCR product of a binary vector containing the cDNA in an antisense orientation; lane 2, PCR products of a binary vector containing the cDNA in a sense orientation; lane 3, PCR product of genomic DNA from plants transformed (T1) with the cDNA in an antisense orientation; lane 4, PCR product of genomic DNA from plants transformed with the cDNA in a sense orientation. 
mentioned above. The expected size $(1.7 \mathrm{~kb})$ of DNA fragment was amplified with both genomic DNAs, demonstrating that the intact sequence of the cDNA was integrated in both T1 plants (Fig. 5, panel B).

There is one $X b a \mathrm{I}$ restriction site at $472 \mathrm{bp}$ from 5 ' end of the cDNA $(1.3 \mathrm{~kb})$. From the $X b a$ I site in the cDNA and the sites that PCR primers anneal, when the PCR products were digested with $X b a \mathrm{I}$, the 1.2 and $0.5 \mathrm{~kb}$ DNA fragments were expected to be produced with the cDNA integrated in a sense orientation, while the two 850 bp DNA fragments were expected with the cDNA which were integrated in an antisense orientation (Fig. 5, panel A). The PCR products of the genomic DNAs of both transformed (T1) plants and of the two binary vectors containing the cDNA used for transformation were digested with $X b a \mathrm{I}$, followed by the Southern hybridization analysis using the ${ }^{32} \mathrm{P}-$ labeled probe of the cDNA (Fig. 5, panel C). The hybridizing bands of the expected size were detected with the respective sample. The results indicated that the cDNA was integrated in the expected orientation in the genomes of plants transformed (T1) with the cDNA in sense and antisense orientations, respectively.

\subsection{The plant shapes of $T 1$ plants}

A good method was not found to express quantitatively the degree of stimulation in branching of plants transformed with the cDNA. Therefore, the actual plant shapes of T1 plants and non-transformed plants are presented in Fig. 6 to give the image of stimulation in branching.

As described above, the buckwheat transformed with the cDNA of a rice MADS box gene were highly stimulated in branching. In addition, Kalanchoe pinnata transformed with the cDNA was also stimulated in branching (Kojima et al. unpublished data). The results were, however, rather unexpected since it has been suggested that the cDNA is a member of AP1 MADS box genes based on the dendrogram analysis (Shinozuka et al., 1999). However, the nucleotide sequences of MADS box genes are highly conserved and very similar among various MADS box genes. Therefore, the results of the dendrogram analysis might not be conclusive. Or, it could be possible that the MADS box genes with very similar sequence have different functions. As the result, it is possible that the cDNA used in this study functions in branching in rice.

Alternatively, stimulation of branching might not be a real function of the cDNA in rice. Because the cDNA was expressed ectopically using the CaMV35S promoter in a heterologous plant system

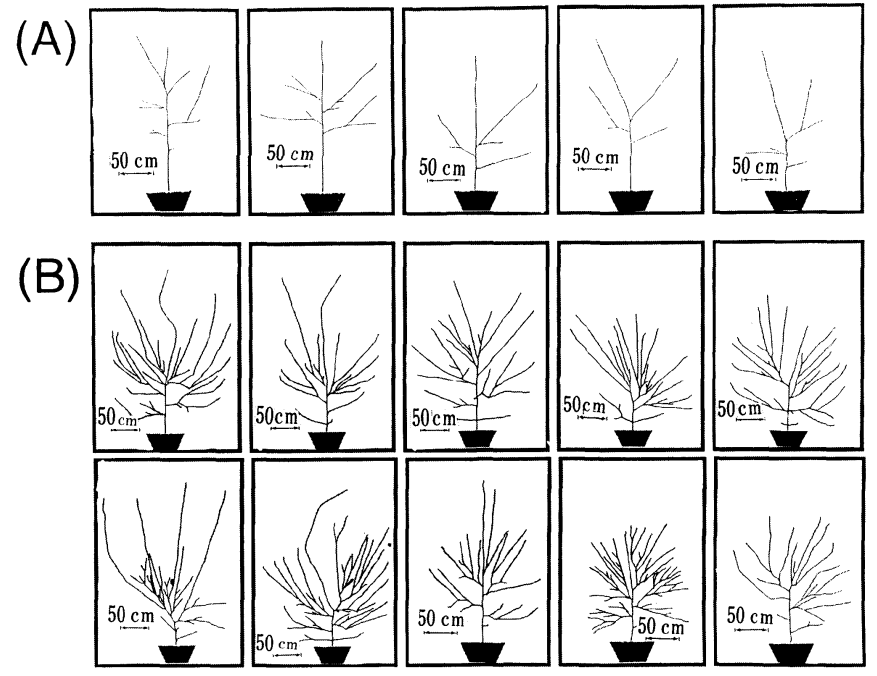

Fig. 6 Shapes of plants of non-transformed and transformed (T1) with the cDNA in a sense oritentation. The plants in panel A are the nontransformed plants which were selected randomly. The plants in panel $\mathrm{B}$ are the $\mathrm{T} 1$ plants transformed with the cDNA in a sense orientation. Ten T0 plants were grown in a pot and pollinated randomly among those plants. The three seeds (T1) from each T0 plant were sown on soils in a pot and grown. The plant in each box of panel B is the one which showed the average degree of branching among the three $\mathrm{T} 1$ plants from one $\mathrm{T} 0$ plant. The lengths of stem and branches were measured 90 days after germination.

in this study. We have a plan to clone an ortholog of the cDNA from buckwheat and study its function in a homologous plant system.

The cDNA of a rice MADS box gene used in this study would be an economically and agriculturally important gene if it could stimulate branching of many other plants besides buckwheat and Kalanchoe even if its real function in rice is not so.

\section{References}

Greco, R., Stagi, L., Colombo, L., Angenet, G. C., SariGorla, M., Pe, M. E., 1997. MADS box genes expressed in developing inflorescences of rice and sorghum. Mol. Gen. Genet., 253: 615-623.

Gustafson-Brown, C., Savidge, B., Yanofsky, M. F. 1994. Regulation of Arabidopsis floral homeotic gene APETALA 1. Cell, 76: 131-143.

Holsters, M., de Waele, D., Depicker, A., Messens, E., Van Montagu, M., Schell, J., 1978. Transfection and transformation of Agrobacterium tumefaciens. Mol. Gen. Gene., 163: 181 - 187.

Kang, H. G., Jang, S., Chung, J. E., Cho, Y., An, G., 1997. Characterization of two rice MADS box genes that control flowering time. Mol. Cells, 7: 559-566.

Kim, Y. S., Lee, H. S., Lee, M. H., Yoo, O. J., Lui, J. R., 1998. A MADS box gene homologous to $\mathrm{AG}$ is 
expressed in seedlings as well as in flowers of ginseng. Plant Cell Physiol., 39: 836-845.

Mandel M. A., Gustafson-Brown, C., Savidge, B., Yanofsky, M. F., 1992. Molecular characterization of the Arabidopsis homeotic gene APETALA1. Nature, 360: $273-277$

Mena, M., Mandel, M. A., Lerner, D. R.., Yanofsky, M. F., Schmidt, R. J., 1995. A characterization of the MADSbox gene family in maize. Plant J., 8: 845-854.

Riechmann, J. L., Meyerowitz, E. M., 1997. MADS domain proteins in plant development. Biol. Chem., 378: 10791101.

Rounsley, S. D., Ditta, G. S., Yanofsky, M. F., 1995. Diverse roles for MADS box genes in Arabidopsis development. Plant Cell, 7: 1259-1269.

Shinozuka, Y., Kojima, S., Shomura, A., Ichimura, H., Yano, M., Yamamoto, K., Sasaki, T., 1999. Isolation and characterization of rice MADS box gene homologoues and their RFLP mapping. DNA Res., 6: 1-7. 